\title{
Modeling and Simulation of Large Synchronous Generator Excitation System with PSASP
}

\author{
Qiao Chen, Li Wan, Kunpeng Zhou, Kai Ding, Jun He, Yuchuan Hu \\ State Grid Hubei Electric Power Research Institute, Wuhan 430077, China
}

Keywords: synchronous generator, excitation system, modeling, simulation.

\begin{abstract}
This article analyzes the different type of large synchronous generator excitation system and discussed the adaptability of the excitation system model of PSASP. A self-excitation model and a three machine excitation model is modeled and simulated, which proves the accuracy of PSASP model.
\end{abstract}

\section{Introduction}

Large generators excitation control system have a significant impact on the static stability, dynamic stability and transient stability of the power system. The results of power system stability calculation will very different when Using different excitation system model and parameters. Therefor we need more accurate mathematical model and parameters that can properly reflect the actual operating state of the equipment, making the results reliable. Providing accurate data for power system stability analysis and daily production scheduling by testing generator excitation system model and parameters will effectively guarantee the security and stability of Gird operation and improve labor productivity, which has important social significance and economic benefits ${ }^{[1-6]}$.

In this paper, a large synchronous generator excitation system model is established through the research on the model of large generator excitation system and simulation tools PSASP, and accuracy of the model is verified by simulation analysis.

\section{Synchronous Generator Excitation System Overview}

Generator excitation system consists of excitation power section, excitation control section, generators voltage measurement, reactive current compensation section and power system stabilizer (PSS), as shown in Fig1.

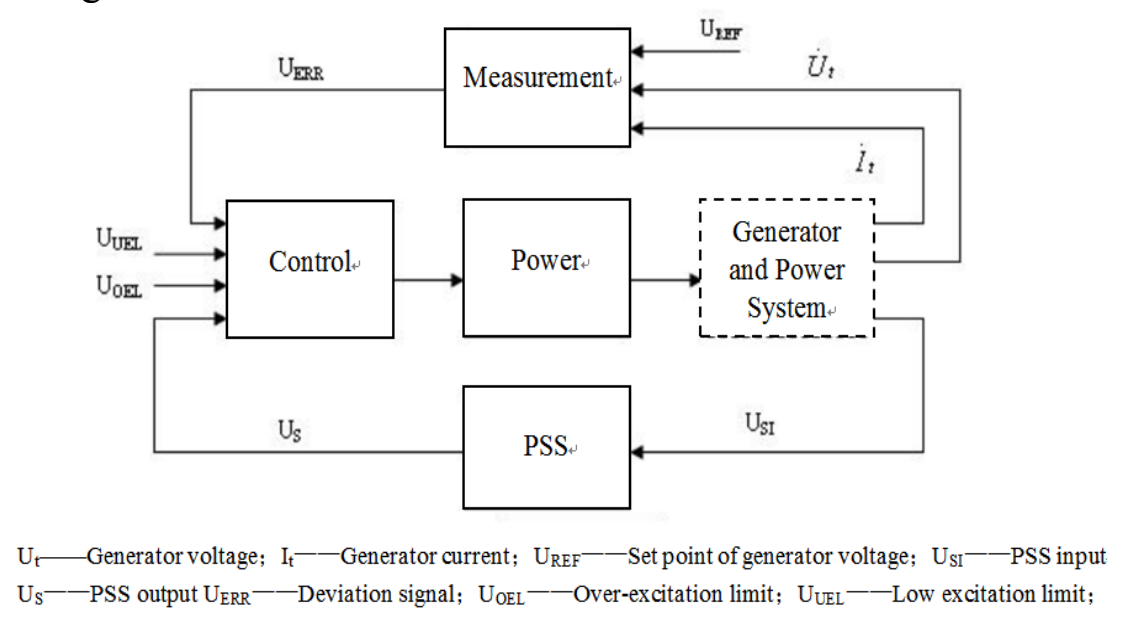

Fig.1 Components of synchronous generator excitation system

Excitation system can be divided into DC exciter excitation system, AC exciter excitation system and static excitation systems according to different power components. Common generator excitation system can be subdivided as shown in Table 1 . 
Table.1 Common classification of synchronous generator excitation system

\begin{tabular}{|c|c|c|c|}
\hline Exciter Type & $\begin{array}{c}\text { Whether the } \\
\text { rectifier controlled }\end{array}$ & $\begin{array}{l}\text { Whether has } \\
\text { pilot exciter }\end{array}$ & Brush /no Bush \\
\hline $\mathrm{DC}$ & 1 & 1 & 1 \\
\hline \multirow{5}{*}{$\mathrm{AC}$} & \multirow{4}{*}{ No } & \multirow{2}{*}{ Yes } & Brush \\
\hline & & & No Brush \\
\hline & & \multirow{2}{*}{ No } & Brush \\
\hline & & & No Brush \\
\hline & Yes & No & \\
\hline \multirow{3}{*}{ Static } & \multicolumn{3}{|c|}{ Self-compound Excitation } \\
\hline & \multicolumn{3}{|c|}{ Self-excitation } \\
\hline & \multicolumn{3}{|c|}{ Constant voltage power supply } \\
\hline
\end{tabular}

Since the capacity of DC exciter is hard to expand because of commutator (commutator) restrictions, it is no longer used in the new production generator sets of $100 \mathrm{MW}$ and above. Currently, most the new large generator put into operation are using self-shunt excitation system or AC excitation system with pilot exciter (referred to three-machine excitation), as shown in Figure 2 and Figure 3.

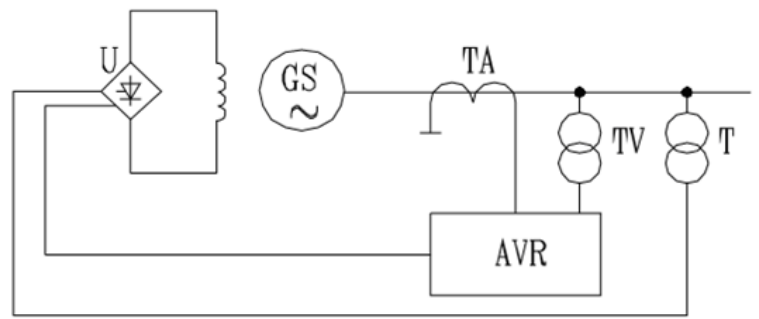

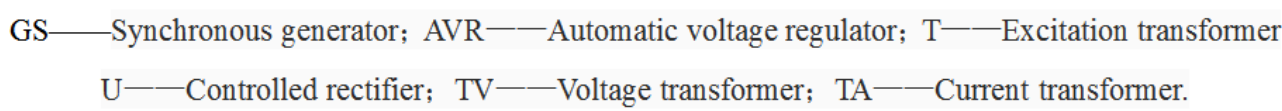

Fig.2 Self-shunt Excitation System

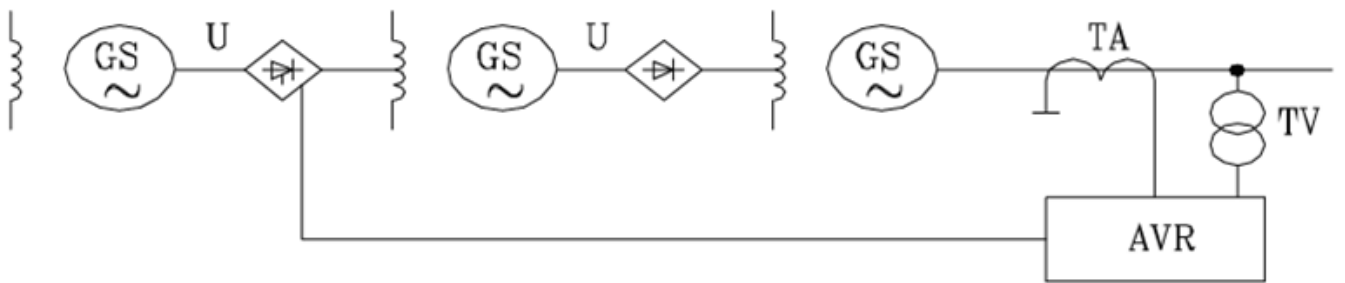

GS_-Synchronous generator; AVR-—Automatic voltage regulator; U-—Rectifier

TV-—Voltage transformer; TA- - Current transformer.

Fig.3 AC Excitation System with pilot exciter(Three-machine Excitation)

\section{PSASP Model of Synchronous Generator Excitation System}

\section{The Excitation System Model in PSASP.}

In PSASP program 14 kinds of excitation regulator model is considered, namely type $1 \sim 14$. Each model are classified according to the exciter type, whether the rectifier is controlled, and with or without pilot exciter characteristics are according to Table 2. 
Table.2 The Excitation System Model in PSASP

\begin{tabular}{|c|c|c|c|c|c|}
\hline $\begin{array}{l}\text { Exciter } \\
\text { Type }\end{array}$ & $\begin{array}{l}\text { Rectifier } \\
\text { controlled } \\
\text { or not }\end{array}$ & $\begin{array}{c}\text { With } \\
\text { pilot } \\
\text { exciter } \\
\text { or not }\end{array}$ & Brush /no Bush & $\begin{array}{l}\text { Type } \\
\text { number }\end{array}$ & Remark \\
\hline \multirow{9}{*}{$\mathrm{AC}$} & \multirow{8}{*}{ No } & \multirow{4}{*}{ Yes } & \multirow[b]{2}{*}{ Brush } & 4 & \\
\hline & & & & 8 & $\begin{array}{l}\text { Parallel correction link is } \\
\text { added to a different location } \\
\text { compared to Type } 4\end{array}$ \\
\hline & & & \multirow[b]{2}{*}{ no Bush } & 3 & \\
\hline & & & & 7 & $\begin{array}{l}\text { Parallel correction link is } \\
\text { added to a different location } \\
\text { compared to Type } 3\end{array}$ \\
\hline & & \multirow{4}{*}{ No } & \multirow[b]{2}{*}{ Brush } & 6 & \\
\hline & & & & 10 & $\begin{array}{l}\text { Parallel correction link is } \\
\text { added to a different location } \\
\text { compared to Type } 6\end{array}$ \\
\hline & & & \multirow[b]{2}{*}{ no Bush } & 5 & \\
\hline & & & & 9 & $\begin{array}{l}\text { Parallel correction link is } \\
\text { added to a different location } \\
\text { compared to Type } 5\end{array}$ \\
\hline & Yes & No & & 11 & \\
\hline \multirow{5}{*}{ Static } & \multicolumn{3}{|c|}{ Separate excitation } & 1 & \\
\hline & \multicolumn{3}{|c|}{$\begin{array}{l}\text { Self-excitation and self-compound } \\
\text { excitation }\end{array}$} & 2 & \\
\hline & \multicolumn{3}{|c|}{ Self-excitation } & 12 & $\begin{array}{l}\text { Voltage source-controlled } \\
\text { rectifier excitation system }\end{array}$ \\
\hline & \multicolumn{3}{|c|}{ Potential source } & 13 & $\begin{array}{l}\text { Potential source-controlled } \\
\text { rectifier excitation system }\end{array}$ \\
\hline & \multicolumn{3}{|c|}{ Self-excitation } & 14 & $\begin{array}{c}\text { For Wuqiangxi Pumped } \\
\text { Storage Plant } \\
\end{array}$ \\
\hline
\end{tabular}

According to selection basis listed in Table 2, we select 12-type model for the self-shunt excitation system; Select 3 type model for the brushless excitation system of three machines; Select 4 type model for the three-machine brush excitation system.

\section{The PID Model in PSASP.}

PID link is the core part of excitation controller, whose parameters determine the characteristics of the generator excitation system. Usually PID segment can be divided into two types of series and parallel.

Serial PID correction usually consists of two lead-lag links, setting the integral correction selection factor $\mathrm{K}_{\mathrm{V}}=1$.

Serial PID transfer function block diagram is:

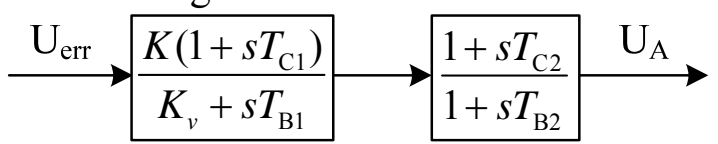

Fig.4 Serial PID transfer function block diagram

Serial PID transfer function is:

$$
\Phi(s)=K \frac{1+s T_{\mathrm{C} 1}}{1+s T_{\mathrm{B} 1}} \frac{1+s T_{\mathrm{C} 2}}{1+s T_{\mathrm{B} 2}}
$$

Because $T_{\mathrm{B} 1}>T_{\mathrm{C} 1}$, setting $\beta=T_{\mathrm{B} 1} / T_{\mathrm{C} 1}=T_{2} / T_{1}>1$, usually $\beta=5 \sim 10$,so $\frac{1+s T_{\mathrm{C} 1}}{1+s T_{\mathrm{B} 1}}$ is lagging link,also known as integral link.

Because $T_{\mathrm{B} 2}<T_{\mathrm{C} 2}$, setting $\gamma=T_{\mathrm{B} 2} / T_{\mathrm{C} 2}=T_{4} / T_{3}<1$, usually $\gamma=0.1 \sim 0.2$, so $\frac{1+s T_{\mathrm{C} 2}}{1+s T_{\mathrm{B} 2}}$ is lead 
link,also known as differential link.

The steady state gain of serial PID is $K_{S}=K$, The dynamic gain is $K_{\mathrm{D}}=K_{\mathrm{S}} / \beta$, and the transient gain is $K_{\mathrm{T}}=K_{\mathrm{D}} / \gamma=K_{\mathrm{S}} /(\beta \gamma)$. It is obvious that $K_{\mathrm{D}}<K_{\mathrm{S}}, K_{\mathrm{D}}<K_{\mathrm{T}}$.

For parallel PID correction, the general transfer function block diagram is:

$$
\Psi(s)=K_{\mathrm{P}}+\frac{K_{\mathrm{I}}}{s}+s K_{\mathrm{D}}
$$

General serial PID correction transfer function is:

$$
\Phi(s)=K \frac{1+s T_{1}}{K_{v}+s T_{2}} \frac{1+s T_{3}}{1+s T_{4}}
$$

When $K_{\mathrm{P}}^{2}-4 K_{\mathrm{D}} K_{\mathrm{I}} \geq 0$ is satisfied, parallel PID transfer function can be converted to serial PID transfer function, setting $K_{v}=0, T_{4}=0$ 。

When this condition can't be satisfied, the transfer function can't be equivalently transformed. We have to use the new parallel PID correction link, and transfer function block diagram is:

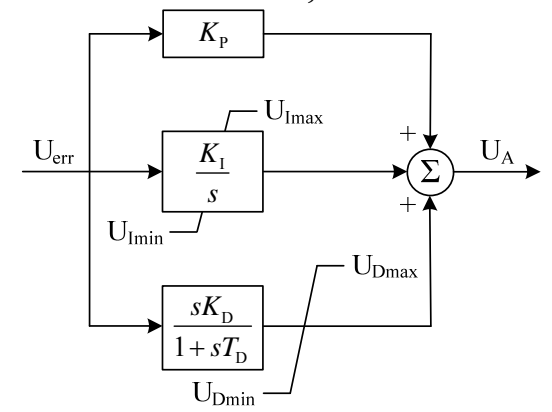

Fig.5 Parallel PID transfer function block diagram

\section{Modeling of Synchronous generator excitation system}

In this paper, A self-excitation generator and a three machine excitation generator in Hubei Province are modeled and simulated respectively.

\section{Modeling and Simulation of Self-excitation generator.}

The Unit 3 of a power plant (hereinafter referred to as the Plant A) in Hubei Province is a capacity of 650MW turbine generator produced by Dongfang Electrical Machinery Co., Ltd., using the self-excitation mode, and its excitation regulator is the type of Unitrol5000 produced by ABB Swiss Company, configured with the Power System Stabilizer (PSS) using power signal and angular velocity signal. The PID excitation transfer function and power system stabilizer (PSS) model diagram is shown in Figure 6.

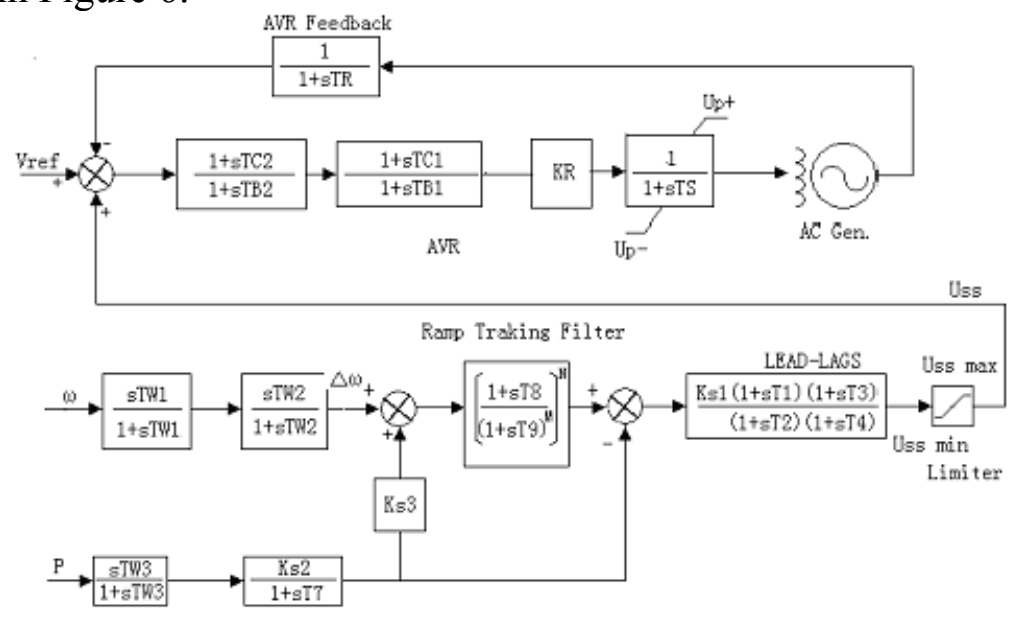

Fig.6 Mathematical model of excitation regulator of Unit 3 in Plant A

According to the information provided by the manufacturer, the excitation regulator parameter setting is shown in Table 3: 
Table.3 Excitation regulator parameter

\begin{tabular}{|c|c|c|}
\hline Paramet & Unit & Value \\
\hline KR & p.u. & 500 \\
\hline TB1 & s & 0.1 \\
\hline TC1 & s & 0.1 \\
\hline TB2 & s & 1.62 \\
\hline TC2 & s & 13.5 \\
\hline
\end{tabular}

So the proportional gain $\mathrm{K}_{\mathrm{p}}=500$, and the equivalent serial PID function expression is:

$$
\Phi(s)=500 \frac{1+1.62 s}{1+13.5 s}
$$

As Unit 3 of Plant A use self-shunt excitation system, we select Type 12 as the excitation system calculation model in PSASP program. Its block diagram is shown in Figure 7, and the parameters shown in Table 4.

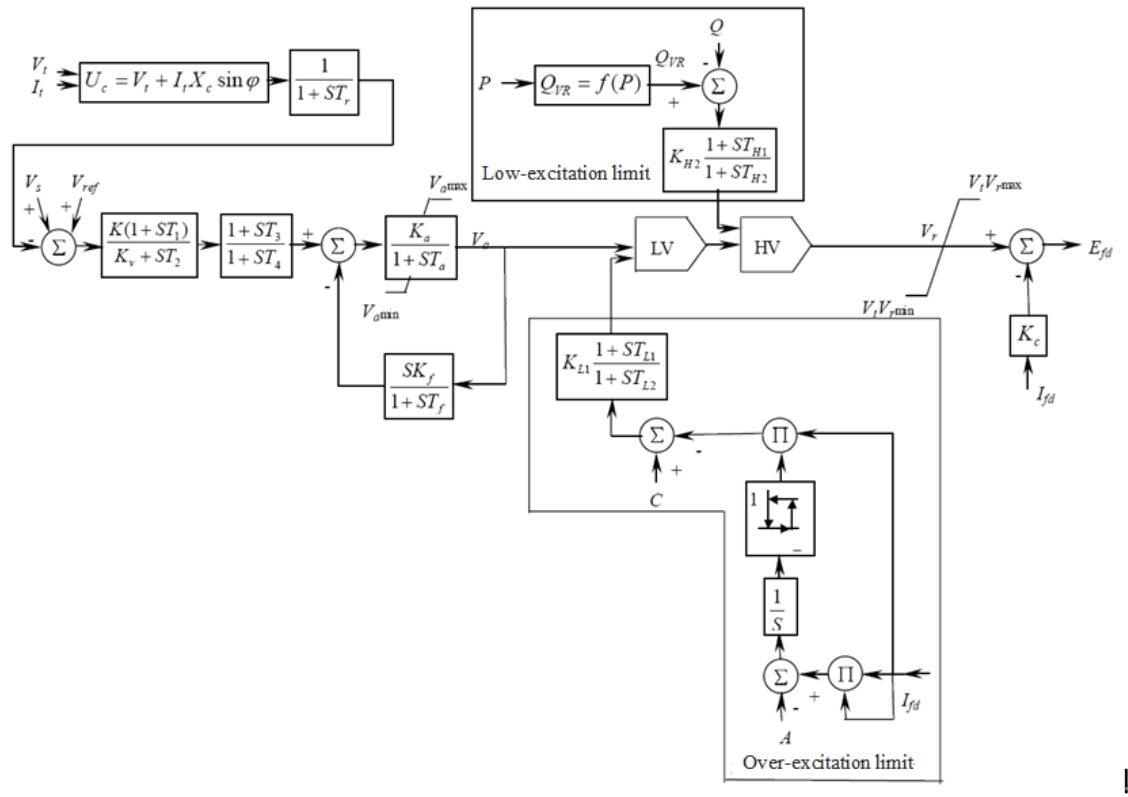

Fig.7 Excitation system block diagram of Type 12

Table.4 Excitation system parameters of Type 12

\begin{tabular}{|c|c|c|c|c|}
\hline Parameter Name & Symbol & Unit & Calculated Value & $\begin{array}{c}\text { Simulation } \\
\text { Value }\end{array}$ \\
\hline Lead Time Constant & $\mathrm{T}_{1}$ & p.u. & 1 & 1 \\
\hline Lag Time Constant & $\mathrm{T}_{2}$ & p.u. & 1 & 1 \\
\hline Lead Time Constant & $\mathrm{T}_{3}$ & p.u. & 1.62 & 1.62 \\
\hline Lag Time Constant & $\mathrm{T}_{4}$ & p.u. & 13.5 & 13.5 \\
\hline PID Gain & $\mathrm{K}$ & p.u. & 500 & 500 \\
\hline Integration Selection Factor & $\mathrm{K}_{\mathrm{v}}$ & p.u. & 1 & 1 \\
\hline Amplifier Gain & $\mathrm{K}_{\mathrm{a}}$ & p.u. & 1 & 1 \\
\hline Amplifier Time Constant & $\mathrm{T}_{\mathrm{a}}$ & $\mathrm{s}$ & 0.01 & 0.01 \\
\hline Soft Negative Feedback Gain & $\mathrm{K}_{\mathrm{f}}$ & p.u. & 0 & 0 \\
\hline $\begin{array}{c}\text { Soft Negative Feedback } \\
\text { Time Constant }\end{array}$ & $\mathrm{T}_{\mathrm{f}}$ & $\mathrm{s}$ & 1 & 1 \\
\hline
\end{tabular}

Now we use the simulation values in table 4 to simulate the $5 \%$ no-load step of generator. Simulation conditions are: Adjust the flow of Single Infinite System to make the generator no-load; Generator terminal voltage is the same as the one in field test before step, and step disturbance 
amplitude and time interval is the same as in field test . Simulation curve is shown in Fig8, and comparison results of response characteristic index are shown in table 5 (take the upward step for analysis).

The table 5 shows that the simulation results are close to measured results (deviations are within the scope of the permit), therefore, the simulation parameters in table 4 can be used as the practical parameters for power system stability calculation.

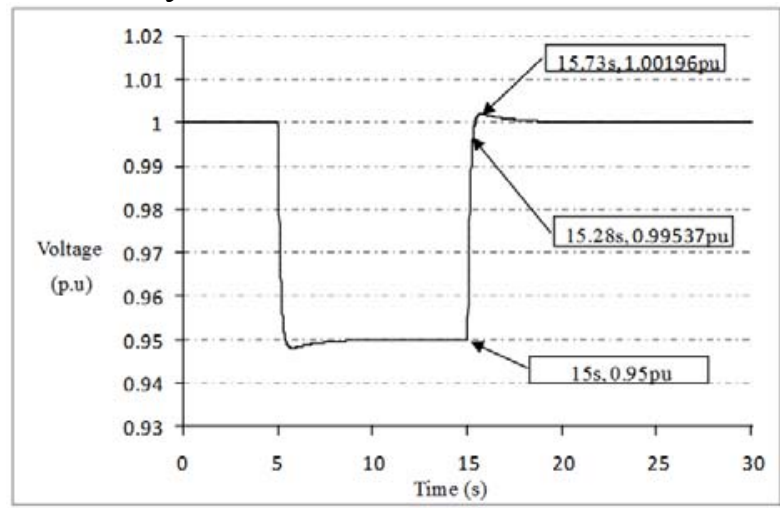

Fig.8 Simulation curve of 5\% no-load voltage step of Unit3 in Plant A

Table.5 Comparison between Test Results and Simulation Results of Generator no-load 5\% Step Response

\begin{tabular}{|c|c|c|c|c|}
\hline Index & Test Results & $\begin{array}{c}\text { Simulation } \\
\text { Results }\end{array}$ & Deviation & $\begin{array}{c}\text { Allowable } \\
\text { Deviation }\end{array}$ \\
\hline Overshoot Amount $\mathbf{M}_{\mathbf{p}}$ & $3.27 \%$ & $3.93 \%$ & $-0.65 \%$ & $\pm 5 \%$ \\
\hline Rise Time $\mathbf{T}_{\mathbf{u p}}(\mathbf{s})$ & 0.22 & 0.28 & -0.06 & \pm 0.1 \\
\hline Peak Time $\mathbf{T}_{\mathbf{p}}(\mathrm{s})$ & 0.6 & 0.73 & -0.13 & \pm 0.2 \\
\hline Adjustment Time $\mathbf{T}_{\mathbf{s}}(\mathrm{s})$ & 0.25 & 0.32 & -0.07 & \pm 2 \\
\hline Number of Oscillation $\mathbf{n}$ & 0.5 & 0.5 & 0.00 & \pm 1 \\
\hline
\end{tabular}

\section{Modeling and Simulation of Three-machine Excitation Generator.}

The Unit 4 of a power plant (hereinafter referred to as the Plant B) in Hubei Province is a capacity of 1000MW turbine generator produced by Shanghai Electrical Machinery Co., Ltd., using the three-machine excitation mode, and its excitation regulator is the type of Unitrol5000 produced by Shanghai ABB engineering Co., Ltd. The PID excitation transfer function and power system stabilizer (PSS) model diagram is shown in Figure 9.

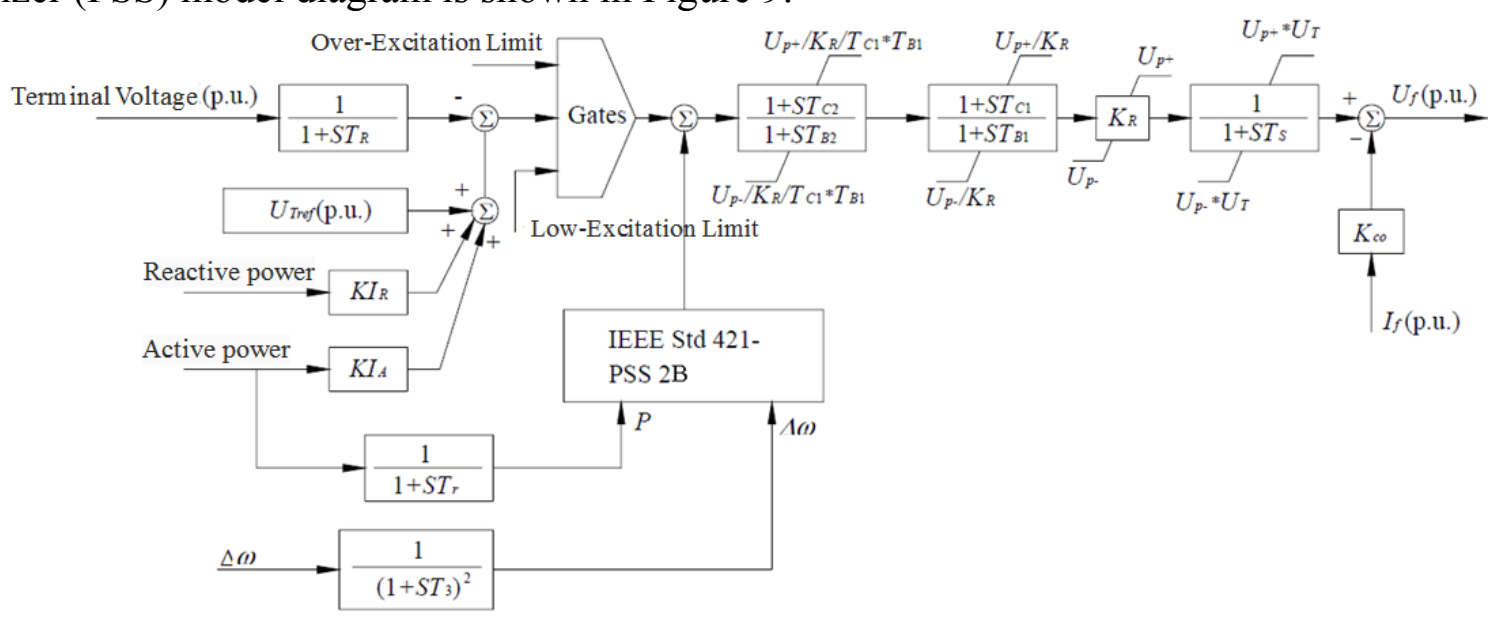

Fig.9 Excitation Regulator PID Mathematical Model of Unit 4 in Plant B According to the information provided by the manufacturer, the excitation regulator parameter setting is shown in Table 6: 
Table.6 AVR Parameters of Unit 3 of Plant B

\begin{tabular}{|c|c|c|}
\hline & Regulator A & Regulator B \\
\hline TR & 0.02 & 0.02 \\
\hline TS & 0.003 & 0.003 \\
\hline KIR & -0.05 & -0.05 \\
\hline KIA & 0 & 0 \\
\hline KR & 400 & 400 \\
\hline TC2 & 0.6 & 0.6 \\
\hline TB2 & 0.16 & 0.16 \\
\hline TC1 & 1.8 & 1.8 \\
\hline TB1 & 40 & 40 \\
\hline
\end{tabular}

So the proportional gain $\mathrm{K}_{\mathrm{p}}=500$, and the equivalent serial PID function expression is:

$$
\Phi(s)=400 \frac{1+2.4 s}{1+32 s} \frac{1+0.4 s}{1+0.12 s}
$$

As Unit 4 of Plant B use three-machine excitation system, we select Type 3 as the excitation system calculation model in PSASP program. This is the uncontrolled rectifier AC exciter excitation system powered by pilot exciter, applicable to the brushless excitation system. Its block diagram is shown in Figure10, and the parameters shown in Table 7.

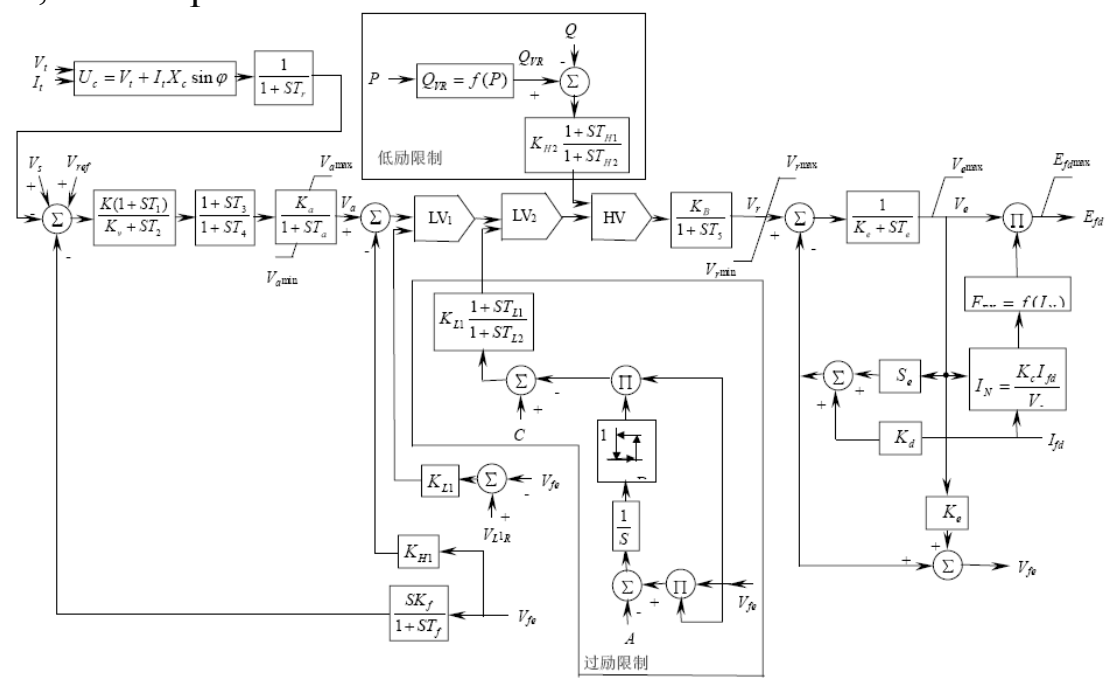

Fig.10 Excitation system block diagram of Type 3

Table.7 Excitation system parameters of Type 3

\begin{tabular}{|c|c|c|c|c|}
\hline Parameter Name & Symbol & Unit & $\begin{array}{c}\text { Calculated } \\
\text { Value }\end{array}$ & $\begin{array}{c}\text { Simulation } \\
\text { Value }\end{array}$ \\
\hline Lead Time Constant & $\mathrm{T}_{1}$ & $\mathrm{~s}$ & 2.4 & 2.4 \\
\hline Lag Time Constant & $\mathrm{T}_{2}$ & $\mathrm{~s}$ & 32 & 32 \\
\hline Lead Time Constant & $\mathrm{T}_{3}$ & $\mathrm{~s}$ & 0.4 & 0.4 \\
\hline Lag Time Constant & $\mathrm{T}_{4}$ & $\mathrm{~s}$ & 0.12 & 0.12 \\
\hline PID Gain & $\mathrm{K}$ & p.u. & 400 & 400 \\
\hline Integration Selection Factor & $\mathrm{K}_{\mathrm{v}}$ & p.u. & 1 & 1 \\
\hline Amplifier Gain & $\mathrm{K}_{\mathrm{a}}$ & p.u. & 1 & 1 \\
\hline Amplifier Time Constant & $\mathrm{T}_{\mathrm{a}}$ & $\mathrm{s}$ & 0.003 & 0.01 \\
\hline Soft Negative Feedback Gain & $\mathrm{K}_{\mathrm{f}}$ & p.u. & 0 & 0 \\
\hline $\begin{array}{c}\text { Soft Negative Feedback Time } \\
\text { Constant }\end{array}$ & $\mathrm{T}_{\mathrm{f}}$ & $\mathrm{s}$ & 4 & 4 \\
\hline Hard Negative Feedback Gain & $\mathrm{K}_{\mathrm{H} 1}$ & p.u. & 0 & 0 \\
\hline
\end{tabular}


Now we use the simulation values in table 7 and excitation system model of Type 3 to simulate the 5\% no-load step of generator in PSASP program. Simulation conditions are: Adjust the flow of Single Infinite System to make the generator no-load; Generator terminal voltage is the same as the one in field test before step, and step disturbance amplitude and time interval is the same as in field test . Simulation curve is shown in Fig11, and comparison results of response characteristic index are shown in table 8 (take the upward step for analysis)。

The table 8 shows that the simulation results are close to measured results (deviations are within the scope of the permit). Therefore, the simulation parameters in table 7 can be used as the practical parameters for power system stability calculation.

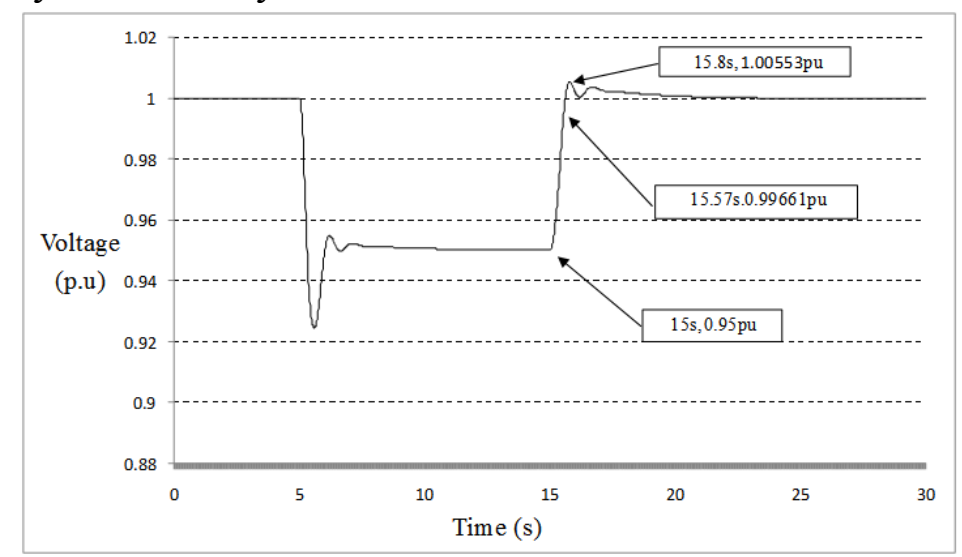

Fig.11 Simulation curve of 5\% no-load voltage step of Unit 4 in Plant B

Table 8 Comparison between Test Results and Simulation Results of Generator no-load 5\% Step Response

\begin{tabular}{|c|c|c|c|c|}
\hline Index & Test Results & $\begin{array}{c}\text { Simulation } \\
\text { Results }\end{array}$ & Deviation & $\begin{array}{c}\text { Allowable } \\
\text { Deviation }\end{array}$ \\
\hline Overshoot Amount $\mathbf{M}_{\mathbf{p}}$ & $21.00 \%$ & $11.06 \%$ & $9.94 \%$ & $10.5 \%$ \\
\hline Rise Time $\mathbf{T}_{\mathbf{u p}}(\mathbf{s})$ & 0.48 & 0.57 & -0.09 & \pm 0.1 \\
\hline Peak Time $\mathbf{T}_{\mathbf{p}}(\mathrm{s})$ & 0.76 & 0.8 & -0.04 & \pm 0.2 \\
\hline Adjustment Time $\mathbf{T}_{\mathbf{S}}(\mathbf{s})$ & 2.1 & 2.53 & -0.43 & \pm 2 \\
\hline Number of Oscillation $\mathbf{n}$ & 1.5 & 2 & -0.5 & $\leq 1$ \\
\hline
\end{tabular}

\section{Conclusion}

In this paper, we have established a self-excitation system and a three excitation system, and completed the modeling and simulation with PSASP. The simulation results show that PSASP modeling have enough accuracy to meet the demand of power system calculation.

\section{Reference}

[1] Wang Liming. Generator Excitation Parameter Measurement and PSS Test Research [J]. Gansu electric power technology, 2006, (4):36-43.

[2] Jiang Liang, Zhu Xiangrong, Yang Liming. Important Function of Excitation Control System in Improving Electric Power System Stability [J]. Machinery manufacturing and automation, 2006, 35(6):163-164.

[3] Guide for Modeling Generator Excitation System. DL/T 1167-2012 : 4-10[S].

[4] You Guangzeng, Si Dajun. Parameter Option for Generator Excitation System in Test and Simulation [J]. Yunnan electric power technology, 2012, 40(6):37-40.

[5] Zhou Kunpeng, Ding Kai, Chen Qiao. Study on the Excitation System Model Building for Unit 
No.6 Jingmen Co-generation Plant [J]. Hubei Electric Power,2014,38（4）:62-65.

[6] Su Weimin, Fang Sili. Typical Mathematics Model and Its Parameter Option for Excitation System[J]. Electric Equipment, 2005, 5(11):27-31

Author Introduce:

Chen Qiao(1988-), Male, Wuhan, Hubei, Engineer, Master's degree, Main research direction: Electrical Engineering.

E-mail : cq198812@,163.com

Cellphone number: 13476169621

QQ: 729912731 